\title{
Vitamin D Is Not an Essential Nutrient for Rora (Labeo rohita) as a Representative of Freshwater Fish
}

\author{
Avadhani Ashok, ${ }^{1}$ Devara Sunita Rao and Namala Raghuramulu* \\ Department of Endocrinology and Metabolism, \\ National Institute of Nutrition, \\ Jamai Osmania P.O., Hyderabad-500007, A.P., India \\ ${ }^{1}$ Sri Sathya Sai Institute of Higher Learning, Prasanthi Nilayam, \\ Ananthapur-515 134, A.P., India
}

(Received May 23, 1997)

\begin{abstract}
Summary This investigation was directed towards finding the need of vitamin D for fish. The freshwater column feeder fish Labeo rohita (Rora) was used for the study. Early fry stage fish were divided into four experimental groups of 350 each: two groups were kept in natural light, while the other two were maintained under total darkness. One each of the light and dark-grown groups was supplied dietary vitamin $D_{3}$ [1,650 i.u/kg diet], whereas the other groups were fed a vitamin D-deficient diet for six months. The known vitamin D-related functions and growth parameters were studied in these four experimental groups of fish. The results showed that fish reared on vitamin D-deficient diet and in dark did not have even traces of liver vitamin $\mathrm{D}$, indicating a state of vitamin $\mathrm{D}$ deficiency in these fish. No significant differences were observed in percent bone to body weight or dry matter of the vitamin D-deficient/ supplemented groups of fish grown in light/dark. Further, it was also observed that there were no significant changes in bone and carcass ash or calcium and phosphorus content in response to vitamin $\mathrm{D}_{3}$ supplementation as compared to the groups which did not receive vitamin $\mathrm{D}_{3}$ (grown both in light and dark). Also, there was little change in several other parameters like carcass protein and lipid, mortality rates, hepatosomatic index, and feed efficiency between the vitamin D-deficient/ supplemented groups of fish. Thus, these findings suggest that vitamin D may not be an essential nutrient for Rora (Labeo rohita) as a representative of freshwater fish.
\end{abstract}

Key Words deficiency, fish, nutrient, Rora, vitamin $\mathrm{D}_{3}$

* To whom correspondence should be addressed. 
Vitamin D, which is produced by the photochemical conversion of 7-dehydrocholesterol (7-DHC) in skin (1-4), is an essential nutrient required for normal growth and mineralization in all terrestrial vertebrates and several functions of its biochemically active form, 1,25-dihydroxy vitamin $\mathrm{D}_{3}\left[1,25-(\mathrm{OH})_{2} \mathrm{D}_{3}\right]$, have been established in these animals (5). However, studies are limited and controversial with regards to the essentiality of this vitamin in fish, the aquatic vertebrates, even though its concentration in these animals can reach relatively high levels $(6-8)$.

The essentiality of this vitamin in the diet (between $500-4,000 \mathrm{i} . \mathrm{u} / \mathrm{kg}$ diet) of catfish, Ictalurus punctatus and rainbow trout, Salmo gairdneri, has been reported by some workers $(9-13)$. However, in many of these studies the typical biochemical parameters, such as bone and blood calcium-phosphorus levels, used to assess vitamin D status did not alter. Also, in none of these studies was the liver vitamin $\mathrm{D}_{3}$ content estimated to show vitamin $\mathrm{D}$ deficiency in fish. However, based on weight gain data only, the authors suggested the essentiality of vitamin D in fish. Further, Barnett et al (12) reported that vitamin $\mathrm{D}_{3}$ was about 3 times more effective than vitamin $\mathrm{D}_{2}$ in promoting the growth of rainbow trout.

On the other hand, some studies have shown no essentiality of vitamin $\mathrm{D}_{3}$ for fish (14-16). Not only diets devoid of vitamin D but also mega doses of vitamin $\mathrm{D}$ supplementation did not seem to affect calcium homeostasis in fish (16).

Thus, there is no definitive evidence from literature for the essentiality of vitamin D in fish. Further, the earlier studies are mostly confined to catfish and rainbow trout.

Very recently, we found that the serum and bone calcium-phosphorus levels were maintained in the same range in several freshwater fish inspite of vast differences in their vitamin D contents (17). This finding suggests no relationship between vitamin $\mathrm{D}$ and its known related parameters in fish. Also, we reported that this vitamin may mostly be derived from their dietary sources (18), as a photochemical mode of synthesis may not be of any significance in their natural habitat $(19,20)$. Therefore, these findings now raise a question: Living in an aquatic environment, where a constant supply of calcium and phosphorus is ensured, is vitamin D essential for fish?

Thus, the objective of this study was to determine the essentiality of vitamin $\mathrm{D}_{3}$ in fish, and study the metabolic consequence of vitamin $\mathrm{D}$ deficiency. The freshwater column feeder fish Labeo rohita (Rora) was used for the study.

\section{MATERIALS AND METHODS}

Chemicals. The source of vitamin $\mathrm{D}_{3}$ and the details of HPLC analysis were already given earlier (17). All other chemicals were of analytical grade procured locally. The purity of standard vitamin $\mathrm{D}_{3}$ was assessed by ultraviolet (UV) spectra as described earlier (17).

Experimental design. The 21-d-old fry of Rora used in the study were obtained 
Table 1. Composition of basal diet.

\begin{tabular}{lr}
\hline Ingredient & $\%$ \\
\hline Casein & 22.9 \\
Gelatin & 14.5 \\
Dextrin & 33.7 \\
Soybean oil & 5.4 \\
Vitamin premix & 0.6 \\
Mineral premix* & 2.4 \\
Cellulose powder & 20.5 \\
\hline
\end{tabular}

The composition of the basal diet is shown in the table.

All ingredients except casein and dextrin were obtained locally. Casein and dextrin were obtained from ICN Pharmaceutical Inc. Life Science Group, Cleveland, Ohio, USA.

*Vitamin and mineral premix as given in Mahajan and Yadave (21).

from the government hatchery at Ananthapur, India. The fish were then acclimatized to the laboratory conditions for two weeks in large plastic pools of 1,000-L capacity before commencement of the experiment. During the period of acclimatization, all the fish were fed with a basal diet deficient in vitamin D.

The acclimatized fish (appr. $102 \pm 5 \mathrm{mg}$ ) were then divided into four groups: two groups were maintained in total darkness, while the other two received natural light for about $12 \mathrm{~h}$ a day. All the pools were aerated $18-20 \mathrm{~h} / \mathrm{d}$. Further, one each of the light and dark-grown groups were fed a diet supplemented with vitamin $\mathrm{D}_{3}[1,650 \mathrm{i} \cdot \mathrm{u} / \mathrm{kg}$ diet ( $+\mathrm{DL}$ and $\left.+\mathrm{DD})\right]$, and the other two groups were fed a diet totally devoid of vitamin $\mathrm{D}_{3}(-\mathrm{DL}$ and $-\mathrm{DD})$. Triplicate groups of 115 fish were used for each dietary treatment.

The basal diet employed for the study (Table 1) was that formulated by Mahajan and Yadave (21).

The ambient water had the following characteristics: temperature, $24.7 \pm 3.2^{\circ} \mathrm{C}$; $\mathrm{pH}, \quad 7.8 \pm 0.3$; dissolved oxygen, $8.6 \pm 0.5 \mathrm{ppm}$; calcium, $34.7 \pm 5.9 \mathrm{ppm}$; and phosphorus, $0.76 \pm 0.05 \mathrm{ppm}$ (mean $\pm \mathrm{SD}$ ).

The fish were fed once a day and were allowed to feed for $6 \mathrm{~h}$ during the same time of the day for a period of six mo. A record was maintained of mortality, feed efficiency, hepatosomatic index and percent bone to body weight, measured at monthly intervals throughout the experimental period.

At the end of the experimental period, the fish were sacrificed and percent bone to body weight, dry matter, bone and carcass ash, bone or carcass calcium and phosphorus, total lipids and proteins of carcass were analyzed. The liver vitamin $\mathrm{D}$ levels were estimated in all four groups of fish.

Liver vitamin $D$ levels. At the conclusion of the experiment, fish were taken at random from each tank, sacrificed, the livers immediately excised and vitamin D assayed in duplicate samples. Each sample represented a pool of about 20-25 
fish livers. The liver vitamin D levels were determined by the HPLC method described earlier (17-19).

Feed efficiency and hepatosomatic index. Feed efficiency was calculated on the basis of feed consumed vs. average body weight. Five fish were used for each dietary treatment and each time interval.

Hepatosomatic index was calculated as percent liver weight to body weight of fish, and five fish were used for the measurement of hepatosomatic index at each time interval for the dietary treatments.

Percent bone to body weight. The vertebral columns of five fish from each dietary treatment were excised, boiled in $0.5 \% \mathrm{NaOH}$ solution for $60 \mathrm{~s}$ to remove the muscle, dried in an oven at $100^{\circ} \mathrm{C}$ overnight and weighed. The percent bone weight to body weight was calculated as follows:

$\frac{\text { bone weight }}{\text { body weight }} \times 100$.

Dry matter. Five fish from each dietary treatment were blotted on a tissue paper and weighed. They were then dried in an oven for $72 \mathrm{~h}$ at $100^{\circ} \mathrm{C}$, cooled and reweighed to determine the dry matter, which is expressed as $\%$.

Bone or carcass ash. The vertebrae of fish $(n=20)$ from each dietary treatment were defatted by refluxing in ether for $16 \mathrm{~h}$ and dried to a constant weight in an oven at $100^{\circ} \mathrm{C}$. The dried bone was ashed in a muffle furnace at $600^{\circ} \mathrm{C}$ for $24 \mathrm{~h}$, and the weight of bone ash content was expressed as \% ash on a fat-free, dry-weight basis.

The dried carcass of fish $(n=20)$ from each dietary treatment was powdered and $1 \mathrm{~g}$ powder in duplicate was placed in a crucible and ashed as described above.

Bone or carcass calcium and phosphorus. The bone or carcass ash was dissolved in $6 \mathrm{~N} \mathrm{HCl}$ and the volume was increased to $100 \mathrm{~mL}$ with water. Calcium and phosphorus were determined as described earlier (17), using appropriate diluted solutions.

Carcass protein and total lipids. About $1 \mathrm{~g}$ of the powdered carcass (dry powder) was used for the estimation of protein and total lipids. Carcass protein was estimated following the Kjeldahl method. The total lipids were extracted with ether using a soxhlet apparatus. The ether was evaporated and the residual lipids were weighed.

Statistical analysis. Values are indicated as the mean plus/minus standard error $(\mathrm{M} \pm \mathrm{SE})$. The statistical differences between the various experimental groups given/not given vitamin $\mathrm{D}_{3}$ and grown in light/dark were assessed by the analysis of variance (ANOVA), and a normal curve test was used for the differences in mortality rates $(22)$.

The experiments were approved by the Ethical Committee on the Use of Animals for Research. 


\section{RESULTS}

\section{Liver vitamin $D$}

Vitamin D status in fish was assessed by the liver vitamin D content. It was observed that vitamin $\mathrm{D}$ in the liver could not be detected in fish not supplemented with this vitamin and grown in the dark ( $-\mathrm{DD}$ group). The liver vitamin D content of fish given vitamin D and grown in the light (+DL group) was found to be $504 \pm 12 \mathrm{ng} / \mathrm{g}$, which is significantly higher than that in the fish which received vitamin D and were grown in the dark ( DD group) $(p<0.001)$ and fish not given vitamin $\mathrm{D}$ and grown in the light $(-\mathrm{DL}$ group) $(p<0.01)$. Fish given vitamin $\mathrm{D}$ and grown in the dark ( + DD group) had marginally, but significantly lower liver vitamin D levels $(p<0.01)$ as compared to those supplemented with vitamin D and grown in the light ( $-\mathrm{DL}$ group). These differences are shown in Table 2.

\section{Percent bone to body weight}

Percentages of bone to body weight of fish are recorded in Table 3. The results showed no significant differences between the four experimental groups at various time intervals (two-way ANOVA).

\section{Dry matter, bone ash and calcium}

Table 4 gives the values of dry matter ( $\%)$, bone ash and calcium of the different experimental groups. As can be seen from the table, no significant effect on $\%$ dry matter was observed in fish fed the vitamin D-deficient diet (-DD and $-\mathrm{DL}$ ) or when supplemented with $1,650 \mathrm{i} \cdot \mathrm{u} / \mathrm{kg}$ diet $(+\mathrm{DL}$ and $+\mathrm{DD})$. Also the $\%$ dry matter values were found to remain unaltered in fish grown in the dark or light (one-way

Table 2. Liver vitamin $D$ levels in fish fed diets supplemented/not given vitamin $D_{3}$ and grown in the light/dark for six months.

\begin{tabular}{ll}
\hline Groups & $\begin{array}{c}\text { Vitamin D content } \\
(\mathrm{ng} / \mathrm{g} \text { liver })\end{array}$ \\
\hline$+\mathrm{DD}$ & $213 \pm 18^{\mathrm{a}}$ \\
$-\mathrm{DD}$ & Not detectable \\
$+\mathrm{DL}$ & $504 \pm 12^{\mathrm{c}}$ \\
$-\mathrm{DL}$ & $360 \pm 44^{\mathrm{d}}$
\end{tabular}

The values are shown as liver vitamin $D$ levels $(M \pm S E)$.

Different superscripts indicate statistical difference between the groups $(p<0.05)$. ANOVA and Dancan's multiple range test were used to test the significance between groups.

+DD: group supplemented with vitamin D and grown in the dark.

-DD: group fed a diet devoid of vitamin D and grown in the dark.

+DL: group supplemented with vitamin D and grown in the light.

- DL: group not given vitamin D and grown in the light. 
Table 3. Vitamin D status and photoperiod on $\%$ bone weight to body weight in Rora grown for six months.

\begin{tabular}{cllll}
\hline \multirow{2}{*}{$\begin{array}{c}\text { Sampling time } \\
\text { (d) }\end{array}$} & \multicolumn{5}{c}{ Group } \\
\cline { 2 - 5 } & \multicolumn{1}{c}{$+\mathrm{DD}$} & \multicolumn{1}{c}{$-\mathrm{DD}$} & \multicolumn{1}{c}{$+\mathrm{DL}$} & $-\mathrm{DL}$ \\
\hline 90 & $0.80 \pm 0.14 \%$ & $0.80 \pm 0.15 \%$ & $0.81 \pm 0.06 \%$ & $0.78 \pm 0.06 \%$ \\
120 & $0.84 \pm 0.20$ & $0.84 \pm 0.22$ & $0.71 \pm 0.08$ & $0.71 \pm 0.06$ \\
150 & $1.04 \pm 0.19$ & $1.02 \pm 0.24$ & $0.80 \pm 0.10$ & $0.81 \pm 0.19$ \\
180 & $0.96 \pm 0.16$ & $1.07 \pm 0.11$ & $0.89 \pm 0.15$ & $0.93 \pm 0.04$ \\
\hline
\end{tabular}

The values are shown as $\%$ of bone weight to body weight $(\mathrm{M} \pm \mathrm{SE})$.

Five fish were used for this experiment.

No significant difference was observed among the groups in each period.

Table 4. \% Dry matter, bone ash and calcium of Rora fed diets supplemented/not given vitamin $\mathrm{D}_{3}$ and grown in the light/dark for six months.

\begin{tabular}{lllll}
\hline \multirow{2}{*}{ Parameter } & \multicolumn{5}{c}{ Group } \\
\cline { 2 - 5 } & \multicolumn{1}{c}{$+\mathrm{DD}$} & \multicolumn{1}{c}{-DD } & \multicolumn{1}{c}{$+\mathrm{DL}$} & \multicolumn{1}{c}{$-\mathrm{DL}$} \\
\hline$\%$ Dry matter (5) & $19.2 \pm 1.3 \%$ & $21.1 \pm 1.1 \%$ & $19.1 \pm 0.7 \%$ & $19.4 \pm 1.7 \%$ \\
$\%$ Bone ash (20) & $48.7 \pm 2.1$ & $44.7 \pm 0.7$ & $45.8 \pm 0.3$ & $47.7 \pm 1.9$ \\
$\%$ Bone calcium (20) & $23.4 \pm 2.0$ & $20.3 \pm 0.3$ & $19.4 \pm 1.0$ & $20.9 \pm 0.8$ \\
\hline
\end{tabular}

The \% dry matter, bone ash and bone calcium were calculated and the values of fish fed diet with vitamin $\mathrm{D}$ or without vitamin $\mathrm{D}$, and also grown in the dark or light, were compared $(\mathrm{M} \pm \mathrm{SE})$.

The figures in parentheses indicate the number of fish used in the experiment.

No significant difference was observed among the groups.

\section{ANOVA).}

The $\%$ bone ash of the fish grown in the light and supplemented with vitamin $\mathrm{D}(+\mathrm{DL})$ was found to be about $46 \%$. Similarly, the $\%$ bone ash values of the other groups (+DD, - DL and -DD), whether given/not given vitamin D and grown in light/dark, did not vary significantly (one-way ANOVA).

The $\%$ bone calcium values also remained similar in the various experimental groups of fish irrespective of their vitamin D status and the photoperiod (one-way ANOVA).

\section{Carcass ash, calcium, phosphorus, protein and lipids}

Table 5 gives the data on carcass ash (\%), calcium, phosphorus, protein and lipids of the various experimental groups of fish. It can be observed from the table that there were no significant differences in the carcass ash values in the vitamin 
Table 5. \% Carcass ash, calcium, phosphorus, protein and lipid of Rora fed diets supplemented/not given vitamin $\mathrm{D}_{3}$ and grown in the light/dark for six months.

\begin{tabular}{cccccc}
\hline \multirow{2}{*}{ Groups } & \multicolumn{5}{c}{ Carcass } \\
\cline { 2 - 6 } & $\begin{array}{c}\text { Ash } \\
(\%)\end{array}$ & $\begin{array}{c}\text { Calcium } \\
(\mathrm{mg} / \mathrm{g})\end{array}$ & $\begin{array}{c}\text { Phosphorus } \\
(\mathrm{mg} / \mathrm{g})\end{array}$ & $\begin{array}{c}\text { Protein } \\
(\mathrm{g} / 100 \mathrm{~g})\end{array}$ & $\begin{array}{c}\text { Lipid } \\
(\mathrm{g} / 100 \mathrm{~g})\end{array}$ \\
\hline +DD (20) & $17.7 \pm 0.5$ & $58.3 \pm 0.8$ & $30.8 \pm 1.0$ & $65.0 \pm 1.2$ & $7.7 \pm 0.4$ \\
-DD (20) & $18.1 \pm 0.1$ & $59.3 \pm 1.3$ & $34.0 \pm 3.0$ & $64.4 \pm 2.7$ & $6.7 \pm 0.5$ \\
+DL (20) & $17.8 \pm 0.1$ & $53.2 \pm 2.8$ & $30.3 \pm 2.0$ & $69.1 \pm 2.3$ & $8.0 \pm 0.3$ \\
-DL (20) & $16.9 \pm 0.3$ & $54.5 \pm 3.0$ & $31.0 \pm 1.0$ & $68.5 \pm 1.5$ & $7.0 \pm 0.3$ \\
\hline
\end{tabular}

The \% carcass ash, calcium, phosphorus, protein and lipid were calculated, and the values of fish fed diet with vitamin $\mathrm{D}$ or without vitamin $\mathrm{D}$, and also grown in the dark or light, were compared $(\mathrm{M} \pm \mathrm{SE})$.

The figures in parentheses indicate the number of fish used in the experiment.

No significant difference was observed among the groups.

Table 6. Vitamin D status and photoperiod on hepatosomatic index in Rora grown for six months.

\begin{tabular}{cllll}
\hline \multirow{2}{*}{$\begin{array}{c}\text { Sampling time } \\
\text { (d) }\end{array}$} & \multicolumn{4}{c}{ Groups } \\
\cline { 2 - 5 } & \multicolumn{1}{c}{$+\mathrm{DD}$} & \multicolumn{1}{c}{$-\mathrm{DD}$} & \multicolumn{1}{c}{$+\mathrm{DL}$} & $-\mathrm{DL}$ \\
\hline 30 & $2.7 \pm 0.26 \%$ & $2.74 \pm 0.65 \%$ & $2.18 \pm 0.32 \%$ & $2.01 \pm 0.45 \%$ \\
60 & $2.02 \pm 0.43$ & $2.66 \pm 0.49$ & $1.75 \pm 0.29$ & $1.87 \pm 0.63$ \\
90 & $2.05 \pm 0.32$ & $2.48 \pm 0.46$ & $1.95 \pm 0.34$ & $2.04 \pm 0.39$ \\
120 & $2.08 \pm 0.26$ & $2.20 \pm 0.16$ & $1.65 \pm 0.26$ & $1.83 \pm 0.37$ \\
150 & $1.73 \pm 0.35$ & $1.84 \pm 0.49$ & $1.41 \pm 0.08$ & $1.28 \pm 0.23$ \\
180 & $1.89 \pm 0.10^{*}$ & $2.16 \pm 0.14 *$ & $1.44 \pm 0.09$ & $1.46 \pm 0.07$ \\
\hline
\end{tabular}

The values are shown as hepatosomatic index (i.e., \% liver weight to body weight) $(\mathrm{M} \pm \mathrm{SE})$.

Five fish were used for this experiment.

Values with superscript $*$ are significantly different from the other groups $(p<0.05)$. ANOVA and Dancan's multiple range test were used to test the significance between groups.

D-deficient and supplemented groups of fish (one-way ANOVA).

The carcass calcium of the -DD group was found to be about $59 \mathrm{mg} / \mathrm{g}$, which is not different from the other experimental groups. Similarly, it was also found that the carcass phosphorus remained unchanged in the groups whether given/not given vitamin D (one-way ANOVA).

It can be seen from Table 5 that fish grown in the light (-DL and $+\mathrm{DL})$ showed marginally higher protein values in comparison to the dark-grown groups. 
However, the values were not statistically significant (one-way ANOVA).

Further, it was also observed that the carcass lipids did not appreciably differ in the vitamin D-deficient and supplemented groups (one-way ANOVA).

Hepatosomatic index, feed efficiency and mortality

Table 6 depicts the values of the hepatosomatic index of the four experimental groups of fish. It can be seen that there were no significant differences between any of the groups till $150 \mathrm{~d}$. By $180 \mathrm{~d}$, the dark-grown groups (+DD and -DD) showed higher values as compared to the light-grown groups ( $-\mathrm{DL}$ and $+\mathrm{DL})(p<0.01)$. In general, the hepatosomatic index decreased only slightly in the period of

Table 7. Effect of vitamin D status and photoperiod on feed efficiency in Rora grown for six months.

\begin{tabular}{ccccc}
\hline \multirow{2}{*}{$\begin{array}{c}\text { Sampling time } \\
(\mathrm{d})\end{array}$} & \multicolumn{4}{c}{ Groups } \\
\cline { 2 - 5 } & $+\mathrm{DD}$ & $-\mathrm{DD}$ & $+\mathrm{DL}$ & $-\mathrm{DL}$ \\
\hline 30 & $2.88 \pm 0.48$ & $2.64 \pm 0.44$ & $2.38 \pm 0.82$ & $2.64 \pm 0.42$ \\
60 & $2.75 \pm 0.51$ & $2.56 \pm 0.27$ & $2.35 \pm 0.63$ & $2.63 \pm 0.51$ \\
90 & $2.38 \pm 0.17$ & $1.57 \pm 0.44$ & $2.14 \pm 0.26$ & $2.31 \pm 0.19$ \\
120 & $1.08 \pm 0.17$ & $0.64 \pm 0.03^{*}$ & $1.12 \pm 0.06$ & $1.19 \pm 0.16$ \\
180 & $1.10 \pm 0.02$ & $0.61 \pm 0.02^{*}$ & $1.16 \pm 0.04$ & $1.15 \pm 0.09$ \\
\hline
\end{tabular}

The values are shown as feed efficiency (i.e., \% feed consumed vs. average body weight $)(\mathrm{M} \pm \mathrm{SE})$.

Five fish were used for this experiment.

Values with superscripts $*$ are significantly different from other groups $(p<0.01$, ANOVA).

Table 8. Effect of vitamin D status and photoperiod on mortality rates in Rora grown for six months.

\begin{tabular}{ccccc}
\hline \multirow{2}{*}{$\begin{array}{c}\text { Sampling time } \\
(\mathrm{d})\end{array}$} & \multicolumn{5}{c}{ Groups } \\
\cline { 2 - 5 } & $+\mathrm{DD}$ & $-\mathrm{DD}$ & $+\mathrm{DL}$ & $-\mathrm{DL}$ \\
\hline 30 & $5.0 \%$ & $4.0 \%$ & $4.3 \%$ & $4.3 \%$ \\
60 & 10.3 & 9.7 & 10.8 & 10.3 \\
90 & 16.0 & 14.0 & 14.3 & 14.3 \\
120 & 18.3 & 17.1 & 17.1 & 17.1 \\
150 & 21.0 & 22.0 & 18.3 & 19.4 \\
180 & 22.0 & 22.6 & 19.0 & 20.6 \\
\hline
\end{tabular}

The values are shown as \% mortality.

No significant difference was observed among the groups in each period. 
$120-180 \mathrm{~d}$.

Also, the feed efficiency remained unchanged in all the experimental groups till $90 \mathrm{~d}$. By $120 \mathrm{~d}$, there was a decrease in the dark-grown group ( $-\mathrm{DD})(p<0.01)$. However, the feed efficiency of the $-\mathrm{DL}$, $+\mathrm{DL}$ and $+\mathrm{DD}$ groups did not vary significantly at any point of time during the experimental period (Table 7).

Further, the mortality records also showed no appreciable differences between any of the experimental groups (Table 8), though the feed efficiency was about $60 \%$ in the - DD group.

\section{DISCUSSION}

The essentiality of vitamin D for fish has not been clearly demonstrated. In this study, this aspect was examined in Rora using a variety of parameters, feeding fish with a diet devoid/supplemented with vitamin D, growing them in the dark/light, and comparing the growth responses.

The fish which did not receive vitamin $\mathrm{D}$ in their diet and were grown in the dark ( $-\mathrm{DD}$ group) did develop vitamin D deficiency as judged by the lack of any detectable level of vitamin $\mathrm{D}$ in the liver. The presence of some amounts of liver vitamin $\mathrm{D}$ in the other groups $(-\mathrm{DL},+\mathrm{DL},+\mathrm{DD})$ suggests that vitamin $\mathrm{D}$ may be derived either from the diet and/or photochemical synthesis.

Lack of any significant differences in the vitamin D-related and/or growth parameters studied in either vitamin D-deficient fish or in fish given vitamin D suggests no known physiological role for this vitamin in these animals. These findings in Rora agree with those of earlier studies using channel catfish (15), gold fish (14) and rainbow trout (16), in which no effect was observed upon supplementation with various doses of vitamin $\mathrm{D}$.

Vitamin D status does not seem to have any influence on percent bone to body weight, bone ash or mineral stores. This finding is contrary to similar studies in terrestrial vertebrates where decreased calcification of bone and hypocalcemia is the classical manifestation of vitamin D deficiency (23-25). It is known that vitamin $\mathrm{D}$ mobilizes calcium via parathyroid hormone (PTH)-mediated response under hypocalcemic conditions in aves and mammals (25). Previous studies have also failed to reveal any typical pattern of bone resorption in teleosts (26). The absence of mineral loss from the Rora skeleton mineral pool in vitamin D deficiency appears to be because of two reasons: i) the parathyroid glands, which produce PTH, are absent; and ii) fish live in a calcium and phosphorus-rich aquatic environment in which a constant supply of these minerals is ensured. Also, the carcass ash, calcium and phosphorus remained unchanged in vitamin D-deficient fish confirming that the known vitamin D-related parameters were not affected.

Similarly, earlier studies using catfish and rainbow trout reported unaltered serum and bone calcium-phosphorus stores in both vitamin D-deficient and supplemented fish $(10,12,13)$. Also, it was shown that bone development was normal in vitamin D-deficient fish. Further, fingerlings of fish were used for these studies. 
In this study, early fry stage fish were fed a vitamin D-deficient diet to give a more clear view of the essentiality of this vitamin. Lack of any change in carcass and bone mineral stores in the vitamin D-deficient fish indicates that this vitamin may not be essential for fish.

Also, it was found that carcass lipids and proteins remained unchanged in vitamin D-deficient fish. However, Barnett et al (11) showed increased lipids in fish grown in darkness on a diet deficient in vitamin $\mathrm{D}$ and suggested that increased lipids may indicate a role of vitamin $\mathrm{D}$ in lipid metabolism, or that it could be due to the lethargic condition of the fish with lower energy expenditure. The discrepancy in results may be due to the difference in the age of the fish.

It was also interesting to find that the other growth parameters like dry matter, hepatosomatic index, feed efficiency and mortality rates showed no appreciable difference between the vitamin D-fed and deficient groups (except the decrease in feed efficiency at the 120-d interval in the -DD group and change in hepatosomatic index at the 180-d interval in both dark-grown groups. The possible reason may be due to age: the linear growth, which is a reflection of food utilization, may not be the same when growth is not rapid and also the liver may not grow in proportion to the body). This indicates that vitamin $\mathrm{D}$ is not an essential nutrient for Rora (Labeo rohita) as a representative of freshwater fish.

Taken together, all of these observations show evidence that fish do not seem to require vitamin $\mathrm{D}$ for bone metabolism and growth-related parameters. In support of this, we observed no relationship between the vitamin $\mathrm{D}$ contents of several freshwater fish and their calcemic/phosphatemic status or bone mineral contents (17).

\section{REFERENCES}

1) Okano T, Yasumura M, Mizuno K, Kobayashi T. 1977. Photochemical conversion of 7-dehydrocholesterol into vitamin $\mathrm{D}_{3}$ in rat skin. J Nutr Sci Vitaminol 23: 165-168.

2) Okano T, Yasumura M, Mizuno K, Kobayashi T. 1978. In vivo and in vitro conversion of 7-dehydrocholesterol into vitamin $\mathrm{D}_{3}$ in rat skin by ultraviolet rays irradiation. $J$ Nutr Sci Vitaminol 24: 47-56.

3) Takada K, Okano T, Tamura Y, Matsui S, Kobayashi T. 1979. A rapid and precise method for the determination of vitamin $\mathrm{D}_{3}$ in rat skin by high-performance liquid chromatography. J Nutr Sci Vitaminol 25: 385-398.

4) Holick MF, MacLaughlin JA, Doppelt SH. 1981. Regulation of cutaneous previtamin $\mathrm{D}_{3}$ photosynthesis in man: skin pigment is not an essential regulator. Science 211: 590-593.

5) Haussler MR. 1986. Vitamin D receptors: nature and function. Ann Rev Nutr 6: 527562.

6) Takeuchi A, Okano T, Ayame M, Yoshikawa H, Teraska S, Murakami Y, Kobayashi T. 1984. High performance liquid chromatographic determination of vitamin $\mathrm{D}_{3}$ in fish liver oils and eel body oils. J Nutr Sci Vitaminol 30: 421-430.

7) Takeuchi A, Okano T, Sayamoto M, Sawamura S, Kobayashi T, Motosugi M, Yamakawa T. 1986. Tissue distribution of 7-dehydrocholesterol, vitamin $\mathrm{D}_{3}$ and 25-hydroxy vitamin $\mathrm{D}_{3}$ in several species of fishes. J Nutr Sci Vitaminol 32: 13-22. 
8) Takeuchi A, Okano T, Torii M, Hatanaka Y, Kobayashi T. 1987. Comparative studies on the contents of vitamin $D_{3}, 25$-hydroxy vitamin $D_{3}$ and 7-dehydrocholesterol in fish liver. Comp Biochem Physiol 88B: 569-573.

9) Lovell RT, Li Y. 1978. Essentiality of vitamin D in diets of channel catfish (Ictalurus punctatus). Trans Am Fish Soc 107: 809-811.

10) Andrews JW, Murai T, Page JW. 1980. Effects of dietary cholecalciferol and ergocalciferol on channel catfish. Aquaculture 19: 49-54.

11) Barnett BJ, Cho CY, Slinger SJ. 1979. The essentiality of cholecalciferol in the diets of rainbow trout (Salmo gairdneri). Comp Biochem Physiol 63A: 291-297.

12) Barnett BJ, Cho CY, Slinger SJ. 1982. Relative biopotency of dietary ergocalciferol and cholecalciferol and the role of and requirement for vitamin $\mathrm{D}$ in rainbow trout (Salmo gairdneri). J Nutr 112: 2011-2019.

13) Brown PB, Robinson EH. 1992. Vitamin D studies with channel catfish (Ictalurus punctatus) reared in calcium-free water. Comp Biochem Physiol 103A(1): 213-219.

14) Sugisaki N, Weicher M, Monder C. 1974. Lack of vitamin $D_{3}$ synthesis by Gold fish (Carassius auratus L). Comp Biochem Physiol 49B: 647-653.

15) Launer CA, Tiemeir OW. 1978. Effects of dietary addition of vitamins $C$ and $D_{3}$ on growth and calcium and phosphorus content of pond cultured channel catfish. Progressive Fish Culturist 40(1): 16-20.

16) Hilton JW, Ferguson HW. 1982. Effect of excess vitamin $D_{3}$ on calcium metabolism in rainbow trout, Salmo gairdneri Richaardson. J Fish Biol 21: 373-379.

17) Sunita Rao D, Raghuramulu N. 1995. Vitamin D and its related parameters in fresh-water wild fishes. Comp Biochem Physiol 111A(2): 191-198.

18) Sunita Rao D, Raghuramulu N. 1996. Food chain as origin of vitamin D in fish. Comp Biochem Physiol 114A(1): 15-19.

19) Sunita Rao D, Raghuramulu N. 1997. Vitamin $D_{3}$ in Tilapia mossambica: Relevance of photochemical synthesis. J Nutr Sci Vitaminol 43: 425-433.

20) Takeuchi A, Okano T, Tanda M, Kobayashi T. 1991. Possible origin of extremely high contents of vitamin $\mathrm{D}_{3}$ in some kinds of fish liver. Comp Biochem Physiol 100A(2): 483-487.

21) Mahajan CL, Yadave JS. 1974. Experiments on synthetic diets for carps. Some preliminary observations and their relevance to aquaculture. $J$ Inl Fish Soc India 6: 178-184.

22) Chiplankas SA, Visweswara Rao K. 1994. Analysis of variance. In: Biostatistics. A Manual of Statistical Methods for Use in Health and Nutrition (Visweswara Rao K, ed), p 262-303. Jaypee Brother's Medical Publishers (P) LH, New Delhi.

23) Okano T, Mizuno K, Kobayashi T. 1978. Identification of determination of 25-hydroxy vitamin $\mathrm{D}_{3}$ in the blood and liver of vitamin D-deficient rats irradiated with ultraviolet light. $J$ Nutr Sci Vitaminol 24: 511-518.

24) Tsugawa N, Okano T, Takeuchi A, Kayama M, Kobayashi T. 1992. Metabolism of orally administered ergosterol and 7-dehydrocholesterol in rats and lack of evidence for their vitamin D biological activity. $J$ Nutr Sci Vitaminol 38: 15-25.

25) Henry HL, Norman AW. 1984. Vitamin D: metabolism and biological actions. Ann Rev Nutr 4: 493-520.

26) Moss ML. 1961. Osteogenesis of acellular teleost fish bone. Am J Anat 108: 99-104. 